\title{
Determination of Trace Metals in Human Seminal Plasma Using Inductively Coupled Plasma Mass Spectrometry and Multivariate Statistical Analyses for Sperm Parameters
}

Masatoki Katayama ${ }^{1 *}$, Satoru Kaneko², Kiyoshi Takamatsu², Takahiro Tsukimura ${ }^{1}$ and Tadayasu Togawa ${ }^{1}$

${ }^{1}$ Department of Functional Bioanalysis, Meiji Pharmaceutical University, 2̃522̃1, Noshio, Kiyose, Tokyo 204̃8588, Japan

${ }^{2}$ Reproduction Center (Gynecology), Ichikawa General Hospital, Tokyo Dental College, Ichikawa, Chiba 272̃0824, Japan

\begin{abstract}
We have simultaneously determined the presence of 30 different trace metals in human seminal plasma by Inductively Coupled Plasma Mass Spectrometry (ICP-MS). To date, high concentrations of metals (e.g. Zn, Cu, Mg and $\mathrm{Fe}$ ) in seminal plasma have been sporadically reported and only few reports have discussed the relationships between trace metals and human semen profiles. Ninety-four seminal plasma specimens were first classified in three groups (normozoospermia, oligozoospermia, and azoospermia) according to the WHO guideline for sperm concentration. No significant differences were found among the three groups for all the metals examined. The concentration of metals in the specimens were then compared with sperm concentration, motility, morphology, and volume using multivariate regression analysis, principal component analysis (PCA) and cluster analysis. The most cumulative contribution ratio and grouping were extracted for profile analysis. $\mathrm{Zn}$ showed a positive correlation with motility and morphology $(r=0.3142$ and 0.6205$)$, whereas trace metals such as Se and $\mathrm{Tl}$ showed positive correlations with all sperm properties. Heavy metals such as $\mathrm{Cu}, \mathrm{Cd}$, and $\mathrm{Cr}$ also showed high positive or negative correlations with sperm properties. In summary, this study is the first to report the simultaneous determination of metals (in addition to the commonly reported $\mathrm{Zn}$ ), including trace and heavy metals, in human seminal plasma as analyzed by multivariate regression analysis.
\end{abstract}

Keywords: Zn; Cd; Cr; Pb; Se; ICP-MS; Purified seminal plasma; Semen profile

\section{Introduction}

The general population is usually exposed involuntarily to trace metals through food and water intake or contact with soil, dust, or air. There is growing concern for adverse health effects associated with low-level exposures encountered in the environment. $\mathrm{Cd}, \mathrm{Pb}$, and $\mathrm{Hg}$ are recognized as hazardous metals that the general population is most exposed [1]. The acceptable daily intake (ADI) and permissible exposure limits (PEL) of trace metals have been determined for the whole human body. Mammalian testes produce large quantities of sperm daily, thus it is one of organs most sensitive to cytotoxic agents such as anti-cancer drugs [2,3]. Metals may have adverse consequences for male reproductive health, especially spermatogenesis, even at relatively low levels. $\mathrm{Cr}, \mathrm{Cu}, \mathrm{Mn}, \mathrm{Mo}, \mathrm{Se}$, and $\mathrm{Zn}$, are essential for health maintenance but may be hazardous above allowable limits [4]. Cr, Mn, and $\mathrm{Cu}$, which act as cofactors for a variety of important enzymatic reactions, have been associated with reduced semen quality in rodents and in humans $[5,6]$. Mo is also an important cofactor for a limited number of enzymes and has demonstrated reproductive toxicity in animal studies [7]. However, low doses of metals such as $\mathrm{Cu}$, Se, and $\mathrm{Zn}$ may have protective effects on male reproductive outcomes [8], and may assist in counteracting the effects of $\mathrm{Cd}, \mathrm{Pb}$, or other metals that are hazardous to health [9]. To date, human data on non-occupational exposure to these metals have been limited, lacking, or inconsistent across studies, and those for male reproductive functions are more obscure.

The concentrations of metals in human seminal plasma are typically determined by chelatometric titration $[10,11]$ and absorption spectroscopy $[12,13]$. These popular methods have been used to determine the concentrations of individual metals in prepared sample solutions. In contrast, inductively coupled plasma mass spectrometry (ICP-MS) can be used to simultaneously determine over 30 different metals in the same sample preparation. This is due to its high sensitivity, which is over 1000 times that achieved by chelatometric titration $[10,11]$ and atomic absorption spectroscopy (AA) $[12,13]$.

To evaluate the relationship between metal exposures at environmental levels and male reproductive function, we measured 30 well-studied rich metals and trace metals in human seminal plasma. This was achieved using ICP-MS and compared with semen qualities such as sperm concentration, motility, head morphology, and volume of ejaculate. The metals may affect semen quality either individually or through positive/negative synergetic actions by multiple metals. Most reports have analyzed relationships between one type of metal and the two groups -normozoospermia or abnormalspermia [5-8], or the WHO classified groups - normozoospermia, oligozoospermia, and azoospermia - by Student's $t$-test, the Kruskal-Wallis test, and ANOVA [3-10]. Interestingly, various results were observed, including a significant difference among the WHO groups [4] or no significant difference among the WHO groups [9]. Therefore, data was analyzed not only by regression analysis but also by multivariate analyses (principal component analysis: PCA and cluster analysis) for detailed diagnosis of the relationships between the 28 metals and sperm parameters.

*Corresponding author: Masatoki Katayama, Department of Functional Bioanalysis, Meiji Pharmaceutical University, $\tilde{2} 522 \tilde{1} 1$, Noshio, Kiyose, Tokyo 20̃̃8588, Japan, E-mail: kaneko@tdc.ac.jp

Received July 26, 2013; Accepted August 28, 2013; Published August 30, 2013

Citation: Katayama M, Kaneko S, Takamatsu K, Tsukimura T, Togawa T (2013) Determination of Trace Metals in Human Seminal Plasma Using Inductively Coupled Plasma Mass Spectrometry and Multivariate Statistical Analyses for Sperm Parameters. J Mol Biomark Diagn 4: 147. doi:10.4172/2155-9929.1000147

Copyright: (c) 2013 Katayama M, et al. This is an open-access article distributed under the terms of the Creative Commons Attribution License, which permits unrestricted use, distribution, and reproduction in any medium, provided the original author and source are credited 
Citation: Katayama M, Kaneko S, Takamatsu K, Tsukimura T, Togawa T (2013) Determination of Trace Metals in Human Seminal Plasma Using Inductively Coupled Plasma Mass Spectrometry and Multivariate Statistical Analyses for Sperm Parameters. J Mol Biomark Diagn 4: 147. doi:10.4172/2155-9929.1000147

Page 2 of 7

\section{Material and Methods}

\section{Collection of semen and sperm analyses}

Human ejaculates were obtained from patients who visited the Reproduction Center, Ichikawa General Hospital, Tokyo Dental College. All study participants who provided the ejaculates were briefed about the aim of this study and measurement items before their consent was obtained. The ethical committees of Meiji Pharmaceutical University and Ichikawa General Hospital specifically approved this study. Sperm concentration and motility were measured according to the WHO manual $4^{\text {th }}$ ed [14]. Subjects were dichotomized for multiple logistic regression as either greater or less than WHO reference levels for total sperm count (40 million sperm), concentration (20 million sperm $/ \mathrm{mL}$ ), and motility (50\% motility). Sperm head morphology was evaluated according to the strict criteria of Kruger et al. [15] and 4.0\% normal morphology was used as a cut-off value.

\section{Determination of metals in seminal plasma by ICP-MS}

Materials: All standard solutions and ICP-MS analysis grade nitric acid were purchased from Wako Pure Chem (Osaka, Japan). Pure argon gas (99.999\%) was used for ICP-MS. Calibration curves were made using the Elan DRC setup calibration solution kit (Plasma setup solution, calibration solution) by Perkin-Elmer Japan (Yokohama, Japan) and Wako (Wako, Japan).

Sample preparation: Semen samples were centrifuged at 18,000 $\mathrm{rpm}$ for $15 \mathrm{~min}$ and the seminal plasma in the supernatant was collected. This was then treated with equal volumes of $0.5 \%(\mathrm{w} / \mathrm{v})$ nitric acid in accordance with a modified Goullés method [16,17]. The samples $(200$ $\mu \mathrm{L})$ were then diluted $(1: 50)$ in a solution containing $0.01 \% \mathrm{v} / \mathrm{v}$ Triton $\mathrm{X}-100$ and $0.5 \% \mathrm{v} / \mathrm{v}$ nitric acid. The blank samples were prepared in the same way. Diluted Milli-Q water (specific resistance 18.3 M $\Omega$ ) was used in all analyses.

ICP-MS analysis: Perkin-Elmer Elan DR3 was used for the analyses of 30 metals. The instrument conditions used were: Spray chamber: Cyclonic, Nebulizer: Meinhald', FR power/W: 1100, nebulizer gas flow (L/min): $0.60-0.90$. Measuring conditions: scan mode: Peak hopping, replicate time (s): 1 , dwell time (ms): 50 , Sweeps: 40 , integration time (ms): 2000, replicates: 3. Multi-element stock solutions containing $1000 \mathrm{mg} / \mathrm{L}$ were obtained from Perkin-Elmer (PerkinElmer, Norwalk, CT, USA), and Standard multi elements mixture solution from Wako (Osaka, Japan). Standards were prepared by serial dilution of stock solutions in $0.01 \% \mathrm{v} / \mathrm{v}$ Triton $\mathrm{X}-100$ and $0.5 \% \mathrm{v} / \mathrm{v}$ nitric acid. Calibration curves for digested samples were prepared by serial dilution of stock solutions in $4.0 \% \mathrm{v} / \mathrm{v}$ nitric acid.

Statistical analysis: Statistical analyses were performed using JMP 10.0.2 software (SAS Institute, Japan). ANOVA, multiple regression analysis, principal component analysis (PCA), and cluster analysis were used for statistical analysis of metals in seminal plasma.

\section{Results and Discussion}

\section{Metal concentrations in human seminal plasma}

Most reports have analyzed relationships between one type of metal and two groups by semen quality; for example, Meeker et al. [1] classified normozoospermia and sperm morphology (50\% normal morphology). The statistical significance or lack thereof was discussed in relation to a single metal and sperm parameters [1,3-8]. Some previous reports have cited that heavy metals such as $\mathrm{Cd}, \mathrm{Hg}$, and $\mathrm{Pb}$ have hazardous impacts on sperm properties (concentration, motility, morphology [1], and cause DNA damage [1,2]). Zn has been well studied because of its significant role in maintaining male reproductive functions [5], particularly sperm quality [9].

Male infertility treatment was provided for three groups of patients classified in accordance to WHO guidelines [14] at the clinical site. Therefore, it was thought that we should analyze the relationship between metal and sperm properties in the three groups. Most studies have analyzed single metals by titration $[10,11]$ and AA $[12,13]$. Instead, we planned to simultaneously analyze a number of different metals in seminal plasma for a comprehensive study of the relationship between metal concentrations and sperm properties. ICP-MS is superior for simultaneous determination of metals and more sensitive than titration and AA. Therefore, we used ICP-MS in this study. $\mathrm{Na}$ and $\mathrm{K}$ concentrations were not determined as their ranges lay outside calibration limits, their concentrations in body fluid are well studied, and they usually maintain constant homeostatic control. The concentrations of the other 28 analyzable metals in human seminal plasma were determined. They varied in a wide range, thus, the specimens were classified into three groups (normozoospermia and oligozoospermia that were more than or under $20 \times 10^{6} / \mathrm{mL}$, respectively, and azoospermia) and the values compared among the three groups (Table 1). We found no significant correlation between the WHO classification in regard to sperm concentration and $\mathrm{Zn}$ concentration by ANOVA. Many reports have observed the importance of Se and Ca in male reproductive functions [1,3-8], but we

\begin{tabular}{|c|c|c|c|}
\hline Metal & Normozoospermia & Oligozoospermia & Azozoospermia \\
\hline & $(n=28)$ & $(n=28)$ & $(n=28)$ \\
\hline $\mathrm{Al}$ & $0.2515 \pm 0.0472$ & $0.2692 \pm 0.0782$ & $0.2420 \pm 0.0127$ \\
\hline As & $0.0171 \pm 0.0127$ & $0.0136 \pm 0.0088$ & $0.0114 \pm 0.0080$ \\
\hline $\mathrm{Ba}$ & $0.0159 \pm 0.0270$ & $0.0192 \pm 0.0188$ & $0.0070 \pm 0.0061$ \\
\hline $\mathrm{Be}$ & $0.0030 \pm 0.0022$ & $0.0002 \pm 0.0019$ & $0.0002 \pm 0.0012$ \\
\hline $\mathrm{Ca}$ & $230.41 \pm 78.332$ & $403.81 \pm 82.683$ & $179.24 \pm 30.812$ \\
\hline $\mathrm{Cd}$ & $0.0002 \pm 0.0006$ & $0.0008 \pm 0.0004$ & $0.0005 \pm 0.0003$ \\
\hline Co & $0.0014 \pm 0.0013$ & $0.0072 \pm 0.0095$ & $0.0053 \pm 0.0082$ \\
\hline $\mathrm{Cr}$ & $0.0322 \pm 0.0162$ & $0.0199 \pm 0.0048$ & $0.0194 \pm 0.0083$ \\
\hline Cs & $0.0010 \pm 0.0015$ & $0.0005 \pm 0.0004$ & $0.0002 \pm 0.0001$ \\
\hline $\mathrm{Cu}$ & $0.5703 \pm 0.2142$ & $0.7601 \pm 0.6854$ & $0.4432 \pm 0.2681$ \\
\hline $\mathrm{Fe}$ & $13.883 \pm 8.4391$ & $17.744 \pm 8.2312$ & $16.212 \pm 8.2680$ \\
\hline $\mathrm{Ga}$ & $0.0501 \pm 0.0671$ & $0.0261 \pm 0.0333$ & $0.0094 \pm 0.0076$ \\
\hline $\mathrm{Hg}$ & $0.0295 \pm 0.0385$ & $0.0218 \pm 0.0297$ & $0.0132 \pm 0.0149$ \\
\hline In & $0.0276 \pm 0.0054$ & $0.0064 \pm 0.0039$ & $0.0024 \pm 0.0006$ \\
\hline $\mathrm{K}$ & $S^{a}$ & $\mathrm{~S}^{\mathrm{a}}$ & $S^{a}$ \\
\hline $\mathrm{Li}$ & $0.4792 \pm 0.2132$ & $0.3721 \pm 0.0723$ & $0.3162 \pm 0.0381$ \\
\hline $\mathrm{Mg}$ & $90.220 \pm 19.483$ & $20.090 \pm 6.5567$ & $78.300 \pm 18.032$ \\
\hline $\mathrm{Mn}$ & $0.0074 \pm 0.0046$ & $0.0065 \pm 0.0013$ & $0.0058 \pm 0.0022$ \\
\hline Mo & $0.0112 \pm 0.0230$ & $0.0031 \pm 0.0014$ & $0.0032 \pm 0.0012$ \\
\hline $\mathrm{Na}$ & $\mathrm{S}^{\mathrm{a}}$ & $\mathrm{S}^{\mathrm{a}}$ & $\mathrm{S}^{\mathrm{a}}$ \\
\hline$P$ & $97.520 \pm 25.711$ & $70.780 \pm 17.687$ & $86.900 \pm 26.860$ \\
\hline $\mathrm{Pb}$ & $0.0361 \pm 0.0153$ & $0.0792 \pm 0.0322$ & $0.0474 \pm 0.0131$ \\
\hline $\mathrm{Rb}$ & $0.1130 \pm 0.0129$ & $0.2014 \pm 0.0470$ & $0.1111 \pm 0.0455$ \\
\hline $\mathrm{Se}$ & $0.0618 \pm 0.0654$ & $0.0514 \pm 0.0464$ & $0.0391 \pm 0.0530$ \\
\hline Sn & $0.1195 \pm 0.0082$ & $0.2084 \pm 0.2218$ & $0.1026 \pm 0.0843$ \\
\hline $\mathrm{Sr}$ & $0.0295 \pm 0.0182$ & $0.0257 \pm 0.0154$ & $0.0101 \pm 0.0054$ \\
\hline $\mathrm{TI}$ & $0.0047 \pm 0.0042$ & $0.0031 \pm 0.0019$ & $0.0040 \pm 0.0051$ \\
\hline V & $0.0058 \pm 0.0520$ & $0.0193 \pm 0.0025$ & $0.0013 \pm 0.0137$ \\
\hline $\mathrm{Y}$ & $0.0054 \pm 0.0021$ & $0.0082 \pm 0.0056$ & $0.0013 \pm 0.0013$ \\
\hline $\mathrm{Zn}$ & $6.7984 \pm 5.0121$ & $10.870 \pm 7.7120$ & $9.3004 \pm 6.4804$ \\
\hline
\end{tabular}

a: $\mathrm{S}$ means over $3000 \mu \mathrm{g} / \mathrm{ml}$

Table 1: Results of element concentrations $(\mu \mathrm{g} / \mathrm{ml})$ in human seminal plasma 
Citation: Katayama M, Kaneko S, Takamatsu K, Tsukimura T, Togawa T (2013) Determination of Trace Metals in Human Seminal Plasma Using Inductively Coupled Plasma Mass Spectrometry and Multivariate Statistical Analyses for Sperm Parameters. J Mol Biomark Diagn 4: 147. doi:10.4172/2155-9929.1000147

found no clear correlation between the three groups [4,9]. Moreover, all the metals examined showed no significant difference among the three groups.

\section{Scattergram and regression analysis of metals in human seminal plasma}

The statistical approaches favored by most reports of relationships between metals and sperm properties are the t-test $[1,3-8]$ and ANOVA [4,9]. However, we could not find a relationship between the three WHO groups by ANOVA. Thus, we applied the multivariate statistical method (regression analysis, PCA, and CL). Using PCA, we were able to determine the main contributing factors from many elements, including metals and sperm number. This report is the first to use the PCA approach to analyze the relationships between metals and sperm properties in human seminal plasma. The scattergrams and regression equations of all 28 metals and sperm properties (sperm concentration, motility, morphology, and semen volume) for all the samples are summarized in Figure 1. The positive correlations $(\mathrm{r} \geq$ $0.250)$ and strong correlations $(r \geq 0.500)$ are represented in yellow and green, respectively. The negative correlations $(r \leq-0.250)$ are indicated in gray. Table 2 summarizes the metals indicative of positive and negative correlations. Metals including $\mathrm{Ba}, \mathrm{Co}, \mathrm{Mo}, \mathrm{Pb}, \mathrm{Se}, \mathrm{Sr}$, and $\mathrm{Tl}$ were positively and negatively correlated with at least two parameters. In particular, Se and $\mathrm{Tl}$ correlated positively with all the parameters examined. $\mathrm{Zn}$ showed a positive correlation with motility and morphology ( $\mathrm{r}=0.3142$ and 0.6205$)$, whereas negative correlations with sperm concentration were weak $(r=-0.2646)$. Thus, $\mathrm{Zn}$ might have positive effects on sperm properties. The heavy metals, $\mathrm{Pb}, \mathrm{Cd}$, and $\mathrm{Cr}$ were considered hazardous to male reproductive functions [1-5]. As expected, $\mathrm{Pb}$ was negatively correlated, whereas $\mathrm{Cd}$ and $\mathrm{Cr}$ showed strong correlations with concentration, motility, morphology, and volume. Statistically, trace metals including $\mathrm{Tl}$ and $\mathrm{Sr}$ showed positive correlations, although their concentrations were extremely low. Thus, their role in male reproductive function remains obscure. An increase in sample number may be necessary for detailed analyses.

\section{Principal component analysis (PCA) of metals in human seminal plasma}

PCA extracted the main contributing factors from many of the elements, including metals and sperm number. We therefore applied PCA to seminal plasma samples to analyze their relationship with the metals in detail. Thus, the sperm concentration, motility, morphology, and volume in metals were analyzed by PCA. Figure 2 details the eigen values and biplots. Most eigen values accumulated over $80 \%$ on PC10. Se was shown to highly contribute to sperm concentration, motility, morphology, and volume by biplot PC1, 2-3. Moreover, Se showed a high correlation with all sperm properties by PC2-3. By PC1-2, In and $\mathrm{Tl}$ showed a high correlation with volume and $\mathrm{Zn}$ was found to correlate with motility. The factor loadings of PCA among sperm properties and metals are shown in Table 3. From the eigen values of PC, hazardous metals in high concentration, including $\mathrm{Cd}$ and $\mathrm{Cr}$, showed high correlations with sperm properties. The trace metals, $\mathrm{Ce}$, $\mathrm{Ga}$, Co, and Li showed high correlations with sperm properties. The three WHO classes were mainly determined using sperm number, followed by motility and morphology. From the biplot of metal and sperm properties, Se and Tl concentrations were found to be key metals

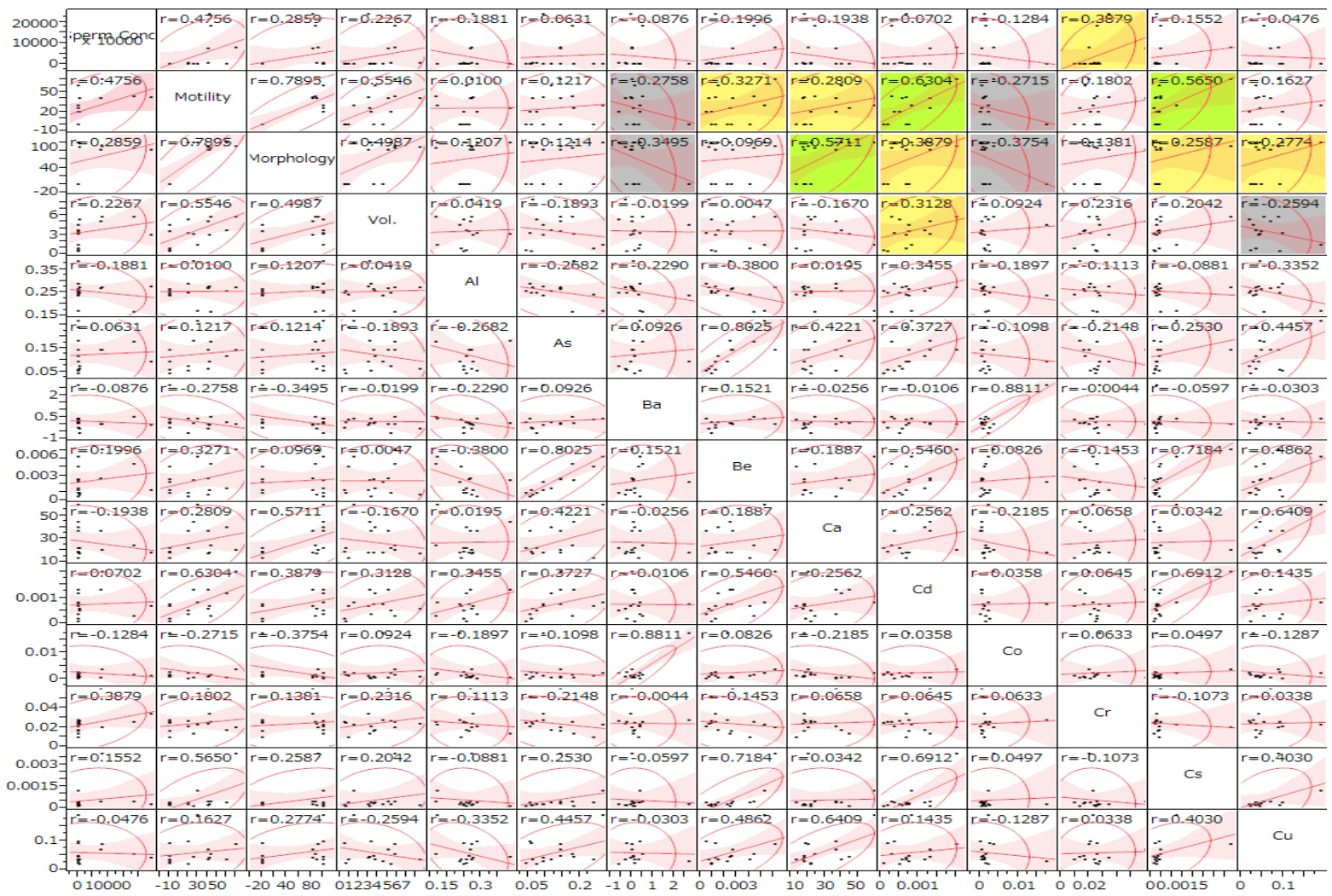

Figure 1a: Correlation matrix of sperm number, motility, morphology, semen volume and 10 metals (Al $-\mathrm{Cu})$. Correlations ( $\mathrm{C} \geq 0.2500)$ among sperm properties are colored in yellow and high correlations $(r \geq 0.5000)$ are colored in green. Negative correlations $(r \leq-0.2500)$ are colored in gray. 
Citation: Katayama M, Kaneko S, Takamatsu K, Tsukimura T, Togawa T (2013) Determination of Trace Metals in Human Seminal Plasma Using Inductively Coupled Plasma Mass Spectrometry and Multivariate Statistical Analyses for Sperm Parameters. J Mol Biomark Diagn 4: 147. doi:10.4172/2155-9929.1000147

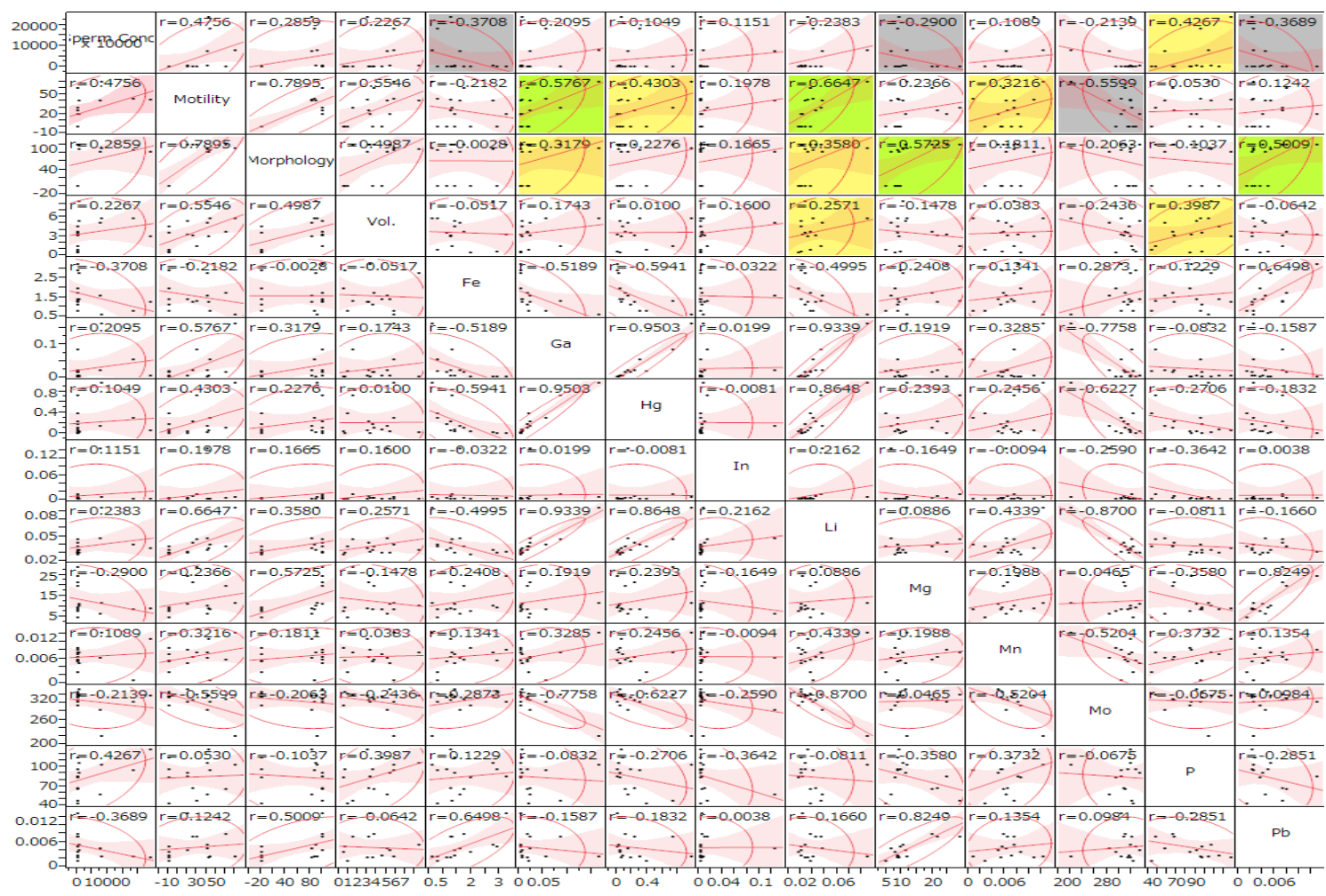

Figure 1b: Correlation matrix of sperm number, motility, morphology, semen volume and 10 metals $(\mathrm{Fe}-\mathrm{Pb})$. Correlations $(r \geq 0.2500)$ among sperm properties are colored in yellow and high correlations $(r \geq 0.5000)$ are colored in green. Negative correlations $(r \leq-0.2500)$ are colored in gray.

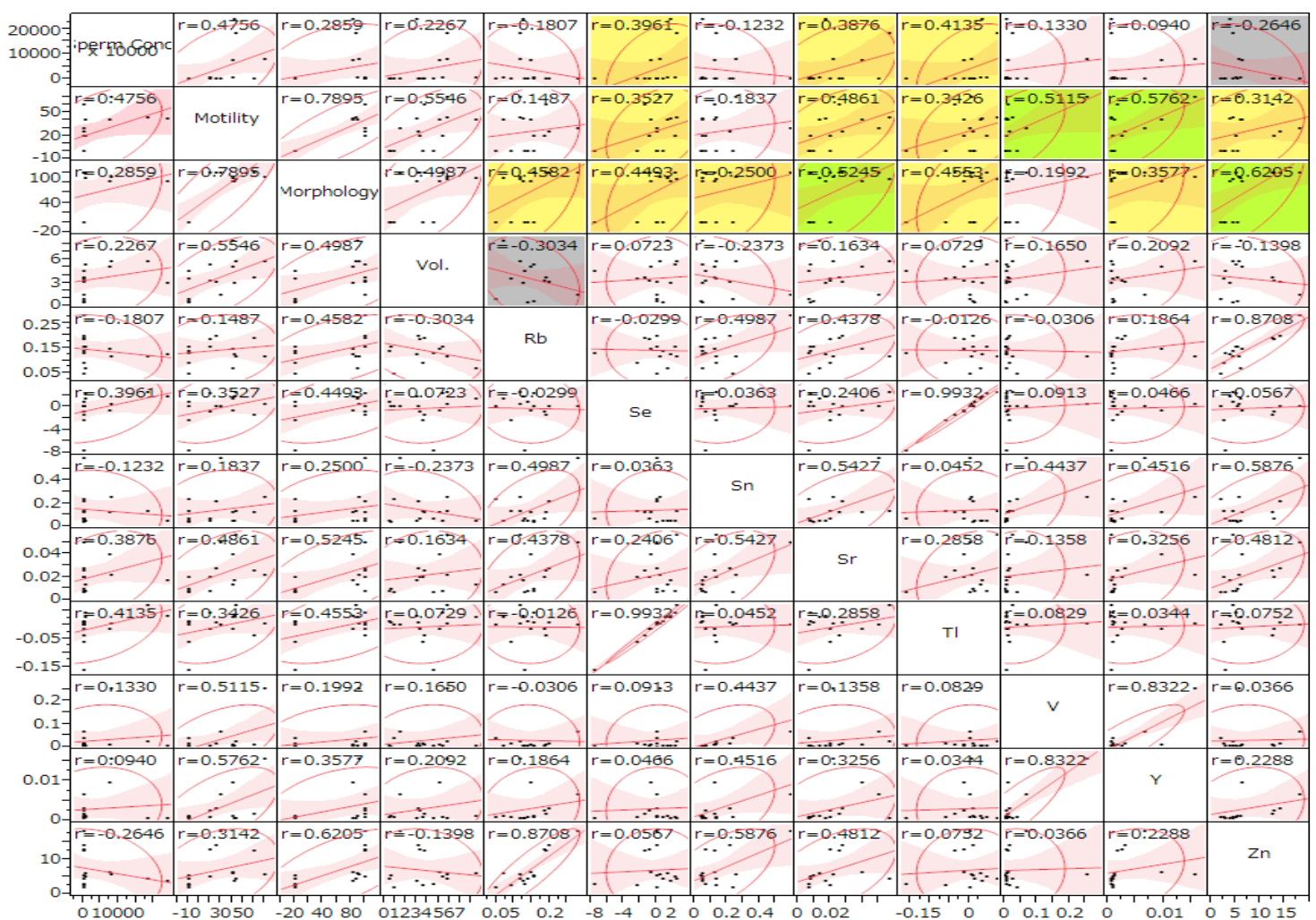

Figure 1c: Correlation matrix of sperm number, motility, morphology, semen volume and 8 metals $(\mathbf{R b}-\mathbf{Z n})$. Correlations $(r \geq 0.2500)$ between sperm properties are colored in yellow and high correlations $(r \geq 0.5000)$ are colored in green. Negative correlations $(r \leq-0.2500)$ are colored in gray. 
Citation: Katayama M, Kaneko S, Takamatsu K, Tsukimura T, Togawa T (2013) Determination of Trace Metals in Human Seminal Plasma Using Inductively Coupled Plasma Mass Spectrometry and Multivariate Statistical Analyses for Sperm Parameters. J Mol Biomark Diagn 4: 147. doi:10.4172/2155-9929.1000147
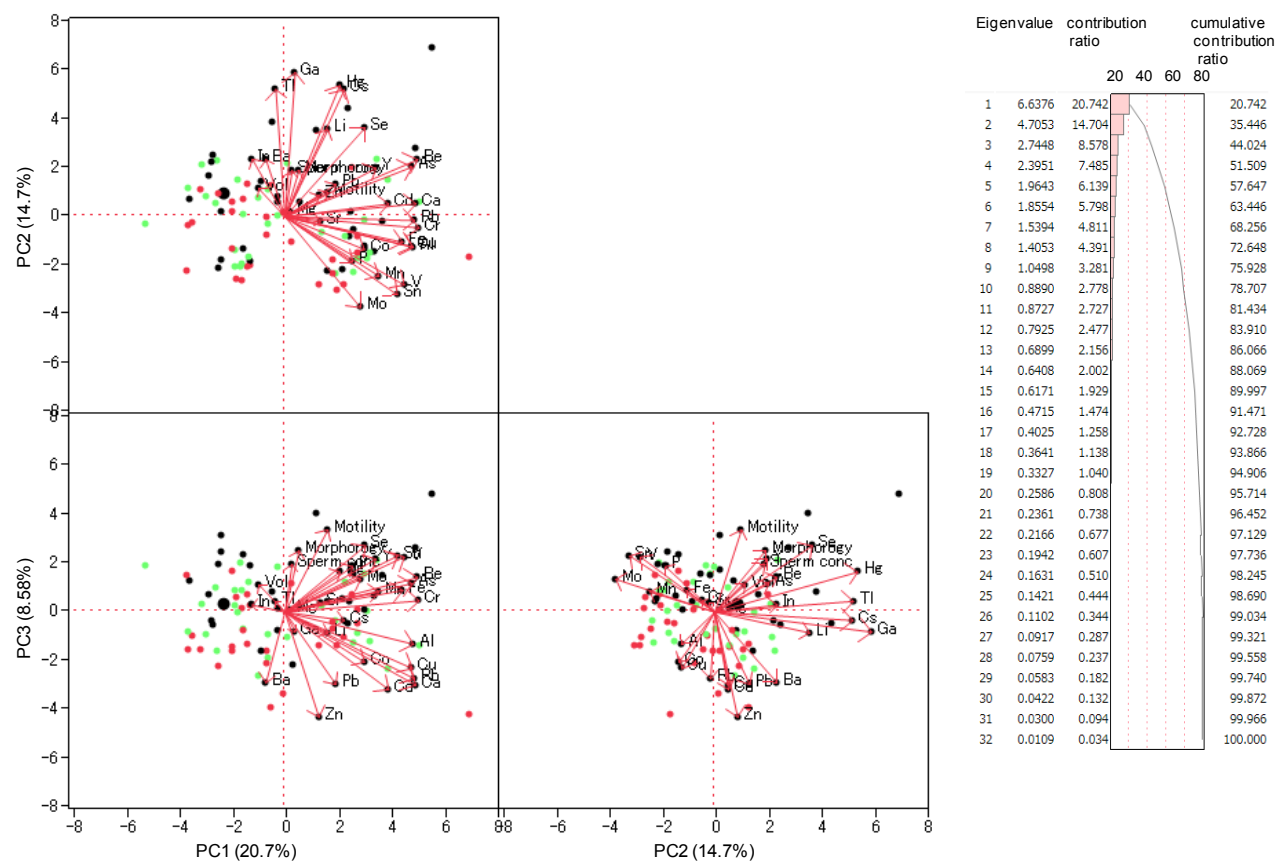

Figure 2: Biplot and eigenvalues among sperm properties and metals.

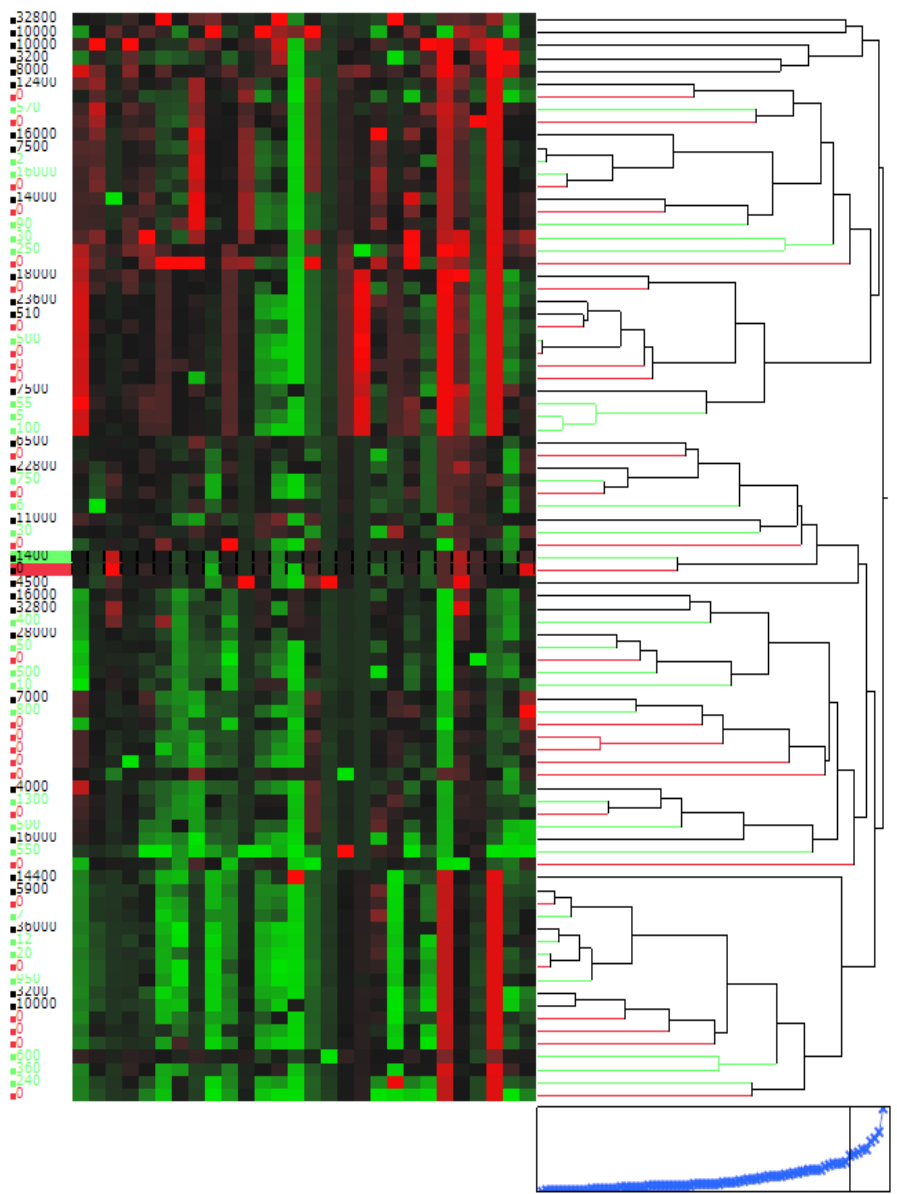

Figure 3: Cluster analysis of sperm properties - metals relationships. Relationships among sperm number - metals, motility - metals, morphology - metals and volume - metals. Groups include normozoospermia (red), oligozoospermia (blue), and azoospermia (green) 
Citation: Katayama M, Kaneko S, Takamatsu K, Tsukimura T, Togawa T (2013) Determination of Trace Metals in Human Seminal Plasma Using Inductively Coupled Plasma Mass Spectrometry and Multivariate Statistical Analyses for Sperm Parameters. J Mol Biomark Diagn 4: 147. doi:10.4172/2155-9929.1000147

Page 6 of 7

\begin{tabular}{|l|c|c|c|}
\hline & Negative correlation & \multicolumn{2}{|c|}{ Positive correlation } \\
\hline Sperm conc. $\left(10^{4} / \mathrm{mL}\right)$ & $\leq-0.250$ & $0.250 \leq$ & $0.500<$ \\
\hline Motility $(\%)$ & $\mathrm{Fe}, \mathrm{Mg}, \mathrm{Pb}, \mathrm{Zn}$ & $\mathrm{P}, \mathrm{Se}, \mathrm{Sr}, \mathrm{Tl}$ & $\mathrm{Cr}$ \\
\hline Morphology $(\%)$ & $\mathrm{Ba}, \mathrm{Co}, \mathrm{Mo}$ & $\mathrm{Be}, \mathrm{Ca}, \mathrm{Hg}, \mathrm{Mn}, \mathrm{Se}, \mathrm{Sr}, \mathrm{Tl}, \mathrm{Zn}$ & $\mathrm{Cd}, \mathrm{Cs}, \mathrm{Ga}, \mathrm{Li}, \mathrm{V}, \mathrm{Y}$ \\
\hline Volume $(\mathrm{mL})$ & $\mathrm{Ba}, \mathrm{Co}, \mathrm{Mo}, \mathrm{Pb}$ & $\mathrm{Cd}, \mathrm{Cs}, \mathrm{Cu}, \mathrm{Ga}, \mathrm{Li}, \mathrm{P}, \mathrm{Rb}, \mathrm{Se}, \mathrm{Sn}, \mathrm{Tl}, \mathrm{Y}$ & $\mathrm{Ca}, \mathrm{Cr}, \mathrm{In}, \mathrm{Mg}, \mathrm{Pb}, \mathrm{Sr}, \mathrm{Zn}$ \\
\hline
\end{tabular}

Table 2: Summary of correlation among metals and sperm properties.

\begin{tabular}{|c|c|c|c|c|c|c|c|c|c|c|}
\hline & PC1 & PC2 & PC3 & PC4 & PC5 & PC6 & PC7 & PC8 & PC9 & PC10 \\
\hline Sperm conc & 0.0387 & 0.2708 & 0.2806 & 0.3286 & 0.4653 & -0.0656 & -0.2924 & -0.2419 & -0.0681 & -0.0281 \\
\hline Motility & 0.2311 & 0.1442 & 0.4837 & 0.3993 & 0.5030 & 0.0055 & -0.2985 & 0.1048 & -0.1420 & 0.0866 \\
\hline Morphorogy & 0.0767 & 0.2732 & 0.3598 & 0.2778 & 0.4181 & -0.1718 & -0.3392 & 0.2671 & -0.0213 & 0.0405 \\
\hline Vol & -0.1413 & 0.1644 & 0.1605 & 0.1173 & 0.1943 & 0.4515 & 0.4192 & 0.1541 & -0.1697 & 0.4491 \\
\hline $\mathrm{Al}$ & 0.6934 & -0.1797 & -0.1885 & 0.3708 & -0.1105 & 0.2362 & -0.0857 & 0.1850 & 0.0677 & 0.0281 \\
\hline As & 0.6855 & 0.2922 & 0.1679 & -0.0992 & -0.2612 & 0.3269 & -0.2239 & -0.0695 & 0.0087 & -0.1031 \\
\hline $\mathrm{Ba}$ & -0.1026 & 0.3349 & -0.4143 & 0.0836 & 0.3007 & -0.1784 & 0.3147 & 0.2775 & -0.0291 & -0.1649 \\
\hline $\mathrm{Be}$ & 0.7159 & 0.3350 & 0.2030 & 0.0317 & -0.2336 & -0.1358 & -0.0157 & 0.0631 & -0.0262 & -0.2524 \\
\hline $\mathrm{Ca}$ & 0.7068 & 0.0760 & -0.4294 & -0.2995 & 0.2429 & -0.2089 & -0.1904 & 0.0813 & -0.0088 & 0.0673 \\
\hline $\mathrm{Cd}$ & 0.5597 & 0.0744 & -0.4552 & 0.4773 & -0.0021 & 0.0159 & 0.1514 & -0.1880 & -0.0967 & 0.0062 \\
\hline Co & 0.4281 & -0.1926 & -0.2931 & -0.0018 & -0.0273 & 0.2283 & 0.1991 & -0.3232 & 0.0288 & 0.2943 \\
\hline $\mathrm{Cr}$ & 0.7241 & -0.0655 & 0.066 & -0.3150 & 0.2024 & -0.0592 & 0.0692 & -0.2848 & -0.1645 & -0.1163 \\
\hline Cs & 0.3202 & 0.7457 & -0.0491 & 0.1654 & -0.0369 & -0.0832 & 0.1056 & -0.3458 & 0.0210 & 0.0249 \\
\hline $\mathrm{Cu}$ & 0.6879 & -0.1764 & -0.3310 & 0.4047 & 0.0130 & 0.0536 & 0.1684 & 0.0831 & -0.0009 & 0.0225 \\
\hline $\mathrm{Fe}$ & 0.6358 & -0.1500 & 0.1280 & -0.4365 & 0.3275 & 0.2856 & 0.0461 & -0.1367 & -0.0715 & -0.2784 \\
\hline $\mathrm{Ga}$ & 0.0551 & 0.8475 & -0.1174 & 0.0047 & 0.0510 & -0.2286 & 0.2326 & -0.0525 & -0.0331 & 0.0923 \\
\hline $\mathrm{Hg}$ & 0.2958 & 0.7706 & 0.2348 & 0.0585 & -0.2481 & -0.1427 & 0.0901 & -0.1628 & -0.0661 & 0.0057 \\
\hline $\ln$ & -0.1765 & 0.3382 & 0.0410 & 0.1207 & 0.3744 & -0.3520 & 0.1467 & -0.3358 & 0.1465 & 0.1249 \\
\hline $\mathrm{Li}$ & 0.2319 & 0.5113 & -0.1217 & -0.2365 & 0.2016 & 0.5761 & -0.0316 & -0.1122 & 0.2794 & -0.1302 \\
\hline $\mathrm{Mg}$ & 0.0274 & 0.0312 & 0.0103 & -0.0871 & 0.4494 & 0.3322 & 0.4161 & 0.3148 & -0.3246 & -0.2747 \\
\hline $\mathrm{Mn}$ & 0.5078 & -0.3488 & 0.1182 & 0.3030 & -0.0288 & -0.0180 & 0.1232 & 0.3165 & -0.0384 & 0.0657 \\
\hline Mo & 0.4079 & -0.5340 & 0.1929 & 0.3652 & -0.1544 & -0.1093 & 0.1517 & -0.0997 & -0.0239 & 0.0354 \\
\hline $\mathrm{P}$ & 0.3656 & -0.2660 & 0.2673 & -0.2862 & 0.1377 & 0.3619 & -0.1972 & -0.1411 & -0.0202 & 0.3674 \\
\hline $\mathrm{Pb}$ & 0.2748 & 0.1888 & -0.4246 & 0.5771 & -0.1802 & 0.2135 & -0.2666 & -0.0061 & -0.1261 & -0.1262 \\
\hline $\mathrm{Rb}$ & 0.6995 & -0.0223 & -0.3918 & -0.2806 & 0.1720 & -0.2167 & -0.1843 & 0.0592 & 0.0210 & 0.2330 \\
\hline Se & 0.4343 & 0.5254 & 0.3896 & -0.1225 & -0.3378 & 0.1134 & -0.0215 & 0.2323 & 0.0214 & 0.0141 \\
\hline Sn & 0.6066 & -0.4584 & 0.3294 & -0.0699 & 0.0627 & -0.3532 & 0.3134 & 0.0228 & 0.0575 & -0.0222 \\
\hline $\mathrm{Sr}$ & 0.1913 & -0.0308 & 0.0520 & 0.1944 & 0.2592 & 0.1060 & 0.0980 & 0.1833 & 0.8383 & -0.0544 \\
\hline $\mathrm{TI}$ & -0.0495 & 0.7475 & 0.0635 & -0.1488 & -0.0843 & 0.0479 & 0.2890 & 0.1906 & 0.0608 & 0.1274 \\
\hline V & 0.6434 & -0.4009 & 0.3237 & -0.1338 & 0.0241 & -0.3298 & 0.2710 & -0.0828 & 0.0701 & -0.0337 \\
\hline$Y$ & 0.4908 & 0.2843 & 0.3119 & -0.1696 & -0.2949 & -0.1442 & -0.0477 & 0.3651 & -0.0157 & 0.1700 \\
\hline $\mathrm{Zn}$ & 0.1831 & 0.1231 & -0.6158 & -0.3953 & 0.1217 & -0.2423 & -0.2541 & 0.3101 & -0.0460 & 0.1208 \\
\hline
\end{tabular}

Table 3: Factor loadings of PCA among sperm properties and metals.

for the diagnosis of male infertility. From these results, we found that in addition to the well-reported metals, Se and $\mathrm{Zn}$, trace metals are also important factors for evaluating sperm profiles.

\section{Cluster analysis of metals in human seminal plasma}

The results of cluster analyses among sperm number, motility, morphology, and volume and metals are shown in Figure 3. Each group was colored as follows: normozoospermia (red), oligozoospermia (blue), and azoospermia (green). Each sample was labeled by sperm number, and all samples were classified into the three main groups. However, each group was inadequately separated by sperm number as shown by the WHO categories. It was shown that sperm properties should be classified not only by sperm concentration but also by cluster analysis. These results were found to be the same using ANOVA analysis of the three WHO classes. Thus, we propose that the metal analysis approach used in this study could be used as a complement method for the diagnosis of male infertility.

\section{Conclusion}

In contrast to previous reports [1-9], all the metals examined in this study provided no clear correlations with the three WHO classes -normozoospermia, oligozoospermia, and azoospermia groups-as assessed by t-tests and ANOVA. However, multivariate analyses, regression analysis, PCA, and CL analysis of whole specimens revealed that metals in human seminal plasma were found to be correlated positively or negatively with various sperm properties. It was revealed that Se and $\mathrm{Tl}$ were key metals for the diagnosis of male infertility by PCA, and this method could be used to complement the diagnosis of male infertility. To verify the accuracy of this analytical approach for use in clinical examinations of male infertility, it is essential to accumulate a large number of specimens as well as examine as many other sperm parameters as possible.

\section{References}

1. Meeker DJ, Rossano MG, Protas B, Diamond MP, Puscheck E, et al. (2008) Cadmium, Lead, and Other Metals in Relation to Semen Quality: Human 
Citation: Katayama M, Kaneko S, Takamatsu K, Tsukimura T, Togawa T (2013) Determination of Trace Metals in Human Seminal Plasma Using Inductively Coupled Plasma Mass Spectrometry and Multivariate Statistical Analyses for Sperm Parameters. J Mol Biomark Diagn 4: 147. doi:10.4172/2155-9929.1000147

Evidence for Molybdenum as a Male Reproductive Toxicant. Environ Health Perspect 116: 1473-1479.

2. Kasimanickam R, Pelzera KD, Kasimanickam VK, Sweckera WS, Thatchera CD (2006) Association of classical semen parameters, sperm DNA fragmentation index, lipid peroxidation and antioxidant enzymatic activity of semen in ramlambs. Theriogenology 66: 1407-1421.

3. Xu DX, Shen HM, Zhu QX, Chua L, Wang QN, et al. (2003) The associations among semen quality, oxidative DNA damage in human spermatozoa and concentrations of cadmium, lead and selenium in seminal plasma. Mutat Res 534: 155-163.

4. Amidu N, Owiredu WKBA, Bekoe MAT, Quaye L (2012) The impact of seminal zinc and fructose concentration on human sperm characteristics. J Medical Biomedical Sci 1: 14-20.

5. Li P, Zhong $Y$, Jiang $X$, Wang C, Zuo Z, et al. (2012) Seminal plasma metals concentration with respect to semen quality. Biol Trace Elem Res148: 16.

6. Li Y, Wu J1, Zhou W, Gao E (2012) Effects of manganese on routine semen quality parameters: results from a population-based study in China. BMC Public Health 12: 919.

7. Apostoli $P(2002)$ Elements in environmental and occupational medicine. J Chromatogr B 778: 63-97.

8. Scott R, MacPherson A, Yates RW, Hussain B, Dixon J (1998) The effect of oral selenium supplementation on human sperm motility. Br J Urol 82: 76-80.

9. Yamaguchi S, Miura C, Kikuchi K, Celino FT, Agusa T, et al. (2009) Zinc is an essential trace element for spermatogenesis. PNAS: 106: 10859-10864.
10. Katayose H, Shinohara A, Chiba M, Yamada H, Tominaga K, et al. (2004) Effects of Various Elements in Seminal Plasma on Semen Profiles. J Mammalian Ova Research 21: 141-148.

11. Fini C, Palmerini CA, Damiani P, Stochaj U, Mannherz HG, et al. (1990) $5^{\prime}$-Nucleotidase from bull seminal plasma, chicken gizzard and snake venom is a zinc metalloprotein. Biochim Biophys Acta 1038: 18̃-22.

12. Dissanayake D, Wijesinghe $P$, Ratnasooriya W, Wimalasena S (2010) Relationship between seminal plasma zinc and semen quality in a subfertile population. J Hum Reprod Sci 3: 124-128.

13. Lin TH, Tseng WC, Cheng SY (1998) Direct determination of selenium in human blood plasma and seminal plasma by graphite furnace atomic absorption spectrophotometry and clinical application. Biol Trace Elem Res 64:133-149.

14. Collection and examination of human semen (1999) In: WHO Laboratory Manual for the Examination of Human Semen and Sperm-Cervical Mucus Interaction. (4thedn), Cambridge, Cambridge University Press, UK, 1999.

15. Kruger TF, Acosta AA, Simmons KF, Swanson RJ, Matta JF, et al. (1988) Predictive value of abnormal sperm morphology in vitro fertilization. Fertil Steril 49: 112-117.

16. Goulle JP, Mahieu L, Castermant J, Neveu N, Bonneau L, et al. (2005) Metal and metalloid multi-elementary ICP-MS validation in whole blood, plasma urine and hair. Reference values. Forensic Sci Int 153: 39-44.

17. Goullé JP, Saussereau E, Mahieu L, Bouige D, Groenwont S, et al. (2009) Application of inductively coupled plasma mass spectrometry multi element analysis in fingernail and toenail as a biomarker of metal exposure. $\mathrm{J}$ Ana Toxicol 33: 92-98. 